\title{
The effects of regular physical activity on adult-onset asthma incidence in women
}

\author{
Marta Benet ${ }^{\text {a,b,c }}$, Raphaëlle Varraso d , Francine Kauffmann ${ }^{\text {d,e }}$, \\ Isabelle Romieu ${ }^{f}$, Josep M. Antó ${ }^{a, b, c, g}$, Françoise Clavel-Chapelon ${ }^{d, e}$, \\ Judith Garcia-Aymerich ${ }^{\text {a,b,c,g,* }}$
}

\footnotetext{
${ }^{a}$ Centre for Research in Environmental Epidemiology (CREAL), Doctor Aiguader 88, 08003 Barcelona, Catalonia, Spain

${ }^{\mathrm{b}}$ Municipal Institute of Medical Research (IMIM-Hospital del Mar), Doctor Aiguader 88, 08003 Barcelona, Spain

${ }^{\mathrm{C}}$ CIBER Epidemiologia y Salud Pública (CIBERESP), Doctor Aiguader 88, 08003 Barcelona, Spain

${ }^{\mathrm{d}}$ National Institute of Health and Medical Research (Inserm), CESP Centre for Research in Epidemiology and Population Health, U1018, Respiratory and Environmental Epidemiology Team, 16, avenue Paul Vaillant Couturier, F-94807 Villejuif, France

e Paris-South University 11, UMRS 1018, F-94807 Villejuif, France

${ }^{f}$ Instituto Nacional de Salud Pública, Col Santa Maria Ahuacatitlan, 62508 Cuernavaca, Morelos, México

${ }^{9}$ Department of Experimental and Health Sciences, Universitat Pompeu Fabra, Doctor Aiguader 88, 08003 Barcelona, Spain
}

Received 11 January 2011; accepted 21 March 2011

Available online 13 April 2011

\section{$\mathrm{MeSH}$ \\ Asthma; Motor activity; \\ Exercise; \\ Incidence; \\ Epidemiology}

\begin{abstract}
Summary
Background: Potential benefit of physical activity in asthma incidence is scarce and controversial. We aimed to assess the association between regular physical activity and adult-onset asthma.

Methods: We included 51,080 women from a French cohort study, and followed them from 1993 to 2003. Physical activity at baseline was defined as time spent in household and leisure time physical activity, converted to metabolic equivalents (METs), and categorised in tertiles. Adult-onset asthma during follow-up was defined according to the American Thoracic Society criteria.

Results: Mean age at baseline was 53 years, 13\% of women were current smokers, $19 \%$ were overweight or obese, and $56 \%$ were postmenopausal; $512(1 \%)$ developed asthma. No association was found between physical activity and asthma incidence in the crude or in the adjusted
\end{abstract}

\footnotetext{
* Corresponding author. Centre for Research in Environmental Epidemiology (CREAL), Doctor Aiguader 88, 08003 Barcelona, Catalonia, Spain. Tel.: +34 9321473 50; fax: +34 932147302.

E-mail address: jgarcia@creal.cat (J. Garcia-Aymerich).
} 
Cox regression model (adjusted HR 1.03 and 1.01 for the 2nd and 3rd tertiles compared to the 1st tertile, $p$ for trend $=0.979$ ).

Conclusion: Physical activity is not related to adult-onset asthma in this cohort of French middle-aged women.

(c) 2011 Elsevier Ltd. All rights reserved.

\section{Introduction}

Adult-onset asthma is an important health problem in terms of prevalence and morbidity, although more research is needed into how its potential risk factors, such as smoking, atopy, or hay fever, are linked to asthma. ${ }^{1,2}$ The consistent reported association between increasing body mass index (BMI) and asthma incidence, ${ }^{1}$ and the finding that regular physical activity reduces the risk of asthma exacerbations in adults, ${ }^{3}$ suggest that physical activity may play a role in the development of adult-onset asthma. A Finnish cohort study of 10,597 adult twins followed for 9 years found that physical activity was associated, among men, with a reduction in asthma risk, while, among women, it was associated with an increased asthma risk, none of these associations being statistically significant. ${ }^{4}$ An 8 -year Danish twin cohort study found physical activity related to a reduction in asthma risk among monozygotic twin pairs $(n=126)$, and to an increase of asthma risk among dizygotic twin pairs $(n=273) .{ }^{5}$ Overall, previous studies have reported controversial results which may be due to the inclusion of highly selected samples, small sample size, and/or shortness of follow-up.

The present study aimed to assess the association between regular physical activity and adult-onset asthma incidence in a large cohort of middle-aged women from the study Étude Epidémiologique auprès de Femmes de l'Education Nationale (E3N). ${ }^{6}$

\section{Methods}

The E3N study started in 1990 when a self-administered questionnaire was sent to all women aged 40-65 years from the Mutuelle Générale de l'Education Nationale, a national health insurance scheme primarily covering teachers, and 98,995 answered. Follow-up questionnaires were sent thereafter approximately every two years. Physical activity was assessed in 1993. Asthma information was obtained by a simple question in 1993, and with a detailed questionnaire in 2003. Thus the present study included women who participated in 1993 (third E3N questionnaire, from now on called "baseline questionnaire") and 2003 (seventh E3N questionnaire) covering a median of 9 years of follow-up. All women signed an informed consent, and Ethics approval was obtained.

Physical activity was obtained from a reduced version of the short European Prospective Investigation of Cancer $(E P I C)^{7}$ physical activity questionnaire with self-reported frequency and duration of recreational physical activity habits (walking, cycling, gardening, home do-it-yourself activities, sports, and climbing stairs) and physical habits at work. A total summary measure in metabolic equivalents (MET) was obtained ${ }^{8}$ and categorised in tertiles. At baseline, asthma status was self-reported as "having ever had asthma attacks". At the end of follow-up, asthma was defined as "asthma attacks ever" together with "a doctor diagnosis", using the American Thoracic Society (ATS) questionnaire, ${ }^{9}$ and age of onset (year of first attack) was obtained. Women were considered to have adult-onset asthma between 1993 and 2003 if they had not reported asthma attacks ever at baseline and met the ATS criteria for asthma definition at follow-up.

Relative risk for asthma onset was estimated using Cox proportional hazards models, with age as the timescale. All women were followed until the first of i) age of asthma onset, or ii) end of follow-up. Potential confounding baseline variables included BMI, smoking status, menopausal status, education level, working status, and relevant co-morbidities (allergic rhinitis, diabetes, cancer, angina pectoris, myocardial infarction, and stroke). Sensitivity analysis included stratification of final models by (i) smoking status, (ii) BMI (less or equal to $25 \mathrm{~kg} / \mathrm{m}^{2}$ and over $25 \mathrm{~kg} / \mathrm{m}^{2}$ ), or (iii) menopausal status (at baseline, at the end of followup, or non menopause), and restriction to women with frequent asthma attacks (at least one per week in the last 12 months). Analyses were performed with SAS version 9 (Cary, NC, USA).

\section{Results}

From a total of 78,083 women who answered our baseline questionnaire, 21,928 were excluded because of missing data on physical activity and/or asthma or did not participate in the follow-up. They were older (53.7 vs. 52.7 years, $p<0.001)$, had higher proportion of active smokers (15.0 vs. $13.3 \%, p<0.001)$ and had higher BMI $\left(23.3 \mathrm{vs} .22 .8 \mathrm{~kg} / \mathrm{m}^{2}\right.$, $p<0.001$ ) than included women. Women that were excluded because of missing physical activity data at baseline had a higher asthma incidence than included women $(1.6 \% \mathrm{vs}$. $1.0 \%, p=0.002)$. We also excluded women who reported having had asthma attacks or doctor diagnosis at baseline $(n=5075)$.

A total of 51,080 women were included, with a mean follow-up of 8.7 years. Out of them, 512 (1\%) developed asthma during follow-up, and mean age at first asthma attack was 57 years. Baseline subjects' characteristics according to asthma incidence are displayed in Table 1. Higher BMI was associated with higher risk of asthma. The Cox regression model adjusted for age, BMI, allergic rhinitis and angina pectoris provided no association between physical activity and asthma incidence (Table 2). Sensitivity analysis, including stratification for BMI, yielded very similar estimates.

\section{Discussion}

Results of the present study do not support the hypothesis that engaging in regular physical activity may reduce adultonset asthma. Results, as seen in previous studies, show 
Table 1 Baseline sociodemographic, lifestyle, and clinical characteristics of 51,080 French women followed for a median of 9 years, according to asthma incidence during follow-up.

\begin{tabular}{|c|c|c|c|c|}
\hline & \multirow{3}{*}{$\frac{\text { All Subjects }}{n=51,080}$} & \multicolumn{2}{|c|}{ Asthma during follow-up } & \multirow[t]{3}{*}{$p$-value } \\
\hline & & No & Yes & \\
\hline & & $n=50,568$ & $n=512$ & \\
\hline Age (years), $m$ (SD) & $53(6.5)$ & $53(6.5)$ & $52(6.3)$ & 0.016 \\
\hline Working status: current worker, $n(\%)$ & $38,600(78.3)$ & $38,200(78.3)$ & $400(81.5)$ & 0.088 \\
\hline \multicolumn{5}{|l|}{ Tobacco smoking } \\
\hline Active smoker, $n(\%)$ & $6736(13.3)$ & $6634(13.2)$ & $102(20.0)$ & \multirow[t]{3}{*}{$<0.001$} \\
\hline Former smoker, $n(\%)$ & $15,378(30.4)$ & $15,213(30.3)$ & $165(32.3)$ & \\
\hline Never smoker, $n(\%)$ & $28,547(56.3)$ & $28,303(56.5)$ & $244(47.7)$ & \\
\hline \multicolumn{5}{|l|}{ Body mass index (BMI) } \\
\hline$<20 \mathrm{~kg} / \mathrm{m}^{2}, \mathrm{n}(\%)$ & 7937 (15.5) & $7886(15.6)$ & $51(10.0)$ & \multirow[t]{4}{*}{$<0.001$} \\
\hline $20-24.9 \mathrm{~kg} / \mathrm{m}^{2}, \mathrm{n}(\%)$ & $33,123(64.9)$ & $32,815(64.9)$ & $308(60.2)$ & \\
\hline $25-29.9 \mathrm{~kg} / \mathrm{m}^{2}, n(\%)$ & $8332(16.3)$ & $8210(16.2)$ & $122(23.8)$ & \\
\hline$\geq 30 \mathrm{~kg} / \mathrm{m}^{2}, n(\%)$ & $1683(3.3)$ & $1652(3.3)$ & $31(6.0)$ & \\
\hline Menopause, $n(\%)$ & $28,457(56.4)$ & $28,178(56.4)$ & $279(55.1)$ & 0.572 \\
\hline Angina Pectoris, $n(\%)$ & $197(0.4)$ & $191(0.4)$ & $6(1.2)$ & 0.004 \\
\hline Allergic Rhinitis, $n(\%)$ & $5121(10.0)$ & $5021(9.9)$ & $100(19.5)$ & $<0.001$ \\
\hline Physical Activity (MET·h/week), m (SD) & $40.17(27.68)$ & $40.2(27.7)$ & $39.4(26.8)$ & 0.521 \\
\hline \multicolumn{5}{|l|}{ Physical Activity group ${ }^{a}$} \\
\hline 1st tertile ( $\leq 24 \mathrm{MET} \cdot \mathrm{h} /$ week), $n(\%)$ & $16,863(33.0)$ & $16,689(33.0)$ & $174(34.0)$ & \multirow[t]{3}{*}{0.835} \\
\hline 2nd tertile ( $>24$ to $\leq 45 \mathrm{MET} \cdot \mathrm{h} /$ week), $n(\%)$ & $16,861(33.0)$ & $16,691(33.0)$ & $170(33.2)$ & \\
\hline 3rd tertile ( $>45 \mathrm{MET} \cdot \mathrm{h} /$ week), $n(\%)$ & $17,356(34.0)$ & $17,188(34.0)$ & $168(32.8)$ & \\
\hline
\end{tabular}

SD: standard deviation; BMI: body mass index; MET: Metabolic Equivalents.

a The value of $24 \mathrm{MET} \cdot \mathrm{h} /$ week is equivalent to walking or doing household work $1 \mathrm{~h}$ per day during seven days a week; $45 \mathrm{MET} \cdot \mathrm{h} /$ week is equivalent to walking or doing household work $2 \mathrm{~h}$ per day during seven days a week, or cycling or practising sports $1 \mathrm{~h}$ per day during seven days a week.

Table 2 Adjusted association between regular physical activity (in tertiles) and asthma incidence during a mean of 8.7 years follow-up of 51,080 middle-aged women.

\begin{tabular}{|c|c|c|}
\hline & $\mathrm{HR}(95 \% \mathrm{Cl})$ & $p$-value \\
\hline Age & $0.98(0.97-0.99)$ & 0.005 \\
\hline \multicolumn{3}{|l|}{ Body Mass Index } \\
\hline$<20 \mathrm{~kg} / \mathrm{m}^{2}$ & $0.67(0.50-0.91)$ & 0.010 \\
\hline$\geq 20$ and $\leq 24.9 \mathrm{~kg} / \mathrm{m}^{2}$ & 1 & \\
\hline$\geq 25$ and $\leq 29.9 \mathrm{~kg} / \mathrm{m}^{2}$ & $1.63(1.32-2.02)$ & $<0.001$ \\
\hline$\geq 30 \mathrm{~kg} / \mathrm{m}^{2}$ & $2.04(1.41-2.95)$ & $<0.001$ \\
\hline Angina Pectoris (yes) & $3.14(1.40-7.06)$ & 0.006 \\
\hline Allergic Rhinitis (yes) & $2.15(1.73-2.68)$ & $<0.001$ \\
\hline \multicolumn{3}{|l|}{ Physical Activity group ${ }^{a}$} \\
\hline $\begin{array}{l}\text { 1st tertile ( } \leq 24 \mathrm{MET} \cdot \mathrm{h} / \\
\text { week) }\end{array}$ & 1 & \\
\hline $\begin{array}{l}\text { 2nd tertile ( }>24 \text { to } \leq 45 \\
\text { MET.h/week) }\end{array}$ & $1.03(0.83-1.27)$ & 0.819 \\
\hline $\begin{array}{l}\text { 3rd tertile }(>45 \mathrm{MET} \cdot \mathrm{h} / \\
\text { week) }\end{array}$ & $1.00(0.81-1.24)$ & 0.981 \\
\hline$P$ for trend & & 0.979 \\
\hline \multicolumn{3}{|c|}{$\begin{array}{l}\text { a The value of } 24 \mathrm{MET} \cdot \mathrm{h} \text { /week is equivalent to walking or } \\
\text { doing household work } 1 \mathrm{~h} \text { per day during seven days a week; } 45 \\
\text { MET-h/week is equivalent to walking or doing household work } \\
2 \mathrm{~h} \text { per day during seven days a week, or cycling or practising } \\
\text { sports } 1 \mathrm{~h} \text { per day during seven days a week. }\end{array}$} \\
\hline
\end{tabular}

a relation between obesity and increased adult asthma risk; however this association would not be explained by physical activity levels. Alternative mechanisms such as reductions in airway calibre as a result of chest wall restriction have been proposed. ${ }^{10}$ It could be argued that physical activity relates to the evolution ${ }^{3}$ but not to the development of the disease, as has been reported for other risk factors of asthma. $^{1}$

A limitation of our study is the potential selection bias due to differences in age, smoking or BMI between participants and non-participants. These differences, although statistically significant, are very small and likely not clinically relevant. The difference in asthma incidence between women with and without physical activity data at baseline could have led to an underestimation of the effects of physical activity on asthma risk. Another limitation - in common with the previous studies - is the possible misclassification both in the measure of physical activity and in asthma diagnosis due to self-reporting, which is difficult to avoid when large sample sizes and long followup periods are needed. However, we favoured a more specific definition of asthma incidence, as it has been suggested that this reduces bias in etiological research. ${ }^{11}$ Finally, current analysis did not include repeated measures of physical activity over time, which has previously been related to underestimation of the effects of physical activity. ${ }^{12}$ Obviously, present results should only be extrapolated to middle-aged women, which limits their external validity. 
We conclude that physical activity is not related to adult-onset asthma in this cohort of French women. Further studies considering changes in physical activity during follow-up, and better measures of both physical activity and asthma, are needed to avoid possible misclassifications and consequent biases. While our study does not support the role of physical activity in asthma incidence, the importance of recommending regular physical activity in adult populations should be stressed for prevention of cardiovascular diseases, cancer and other chronic diseases or conditions. ${ }^{13}$

\section{Conflicts of interest}

None of the authors have any conflicts of interests declared.

\section{Authorship}

All authors have contributed to (i) the conception and design, acquisition of data or analysis and interpretation of data; (ii) the drafting of the article or revising it critically for important intellectual content; and (iii) final approval of the version to be submitted.

\section{Acknowledgements}

The authors are grateful to R Chaït, M Fangon, M Niravong, and $L$ Hoang for managing the data. We are also indebted to all participants for providing data.

The E3N study is being carried out with financial support from the French League against Cancer, the Mutuelle Générale de l'Education Nationale, the Gustave Roussy Institute of Cancérologie and the National Institute of Health and Medical Research. Marta Benet stage at INSERM was funded by Catalan Society of Pneumology (SOCAP). Judith Garcia-Aymerich has a researcher contract from the Instituto de Salud Carlos III (CP05/00118), Ministry of Health, Spain. CIBERESP is funded by the Instituto de Salud Carlos III, Ministry of Health, Spain.

\section{References}

1. Global Strategy for Asthma Management and Prevention. Global Initiative for Asthma (GINA), http://www.ginasthma. org/Guidelineitem. asp??l1 = 2\&l2 =1\&intld=1561; 2009.

2. Antó JM, Sunyer J, Basagaña X, Garcia-Esteban R, Cerveri I, et al. Risk factors of new-onset asthma in adults: a populationbased international cohort study. Allergy 2010;65(8):1021-30.

3. Garcia-Aymerich J, Varraso R, Antó JM, Camargo Jr CA. Prospective study of physical activity and risk of asthma exacerbations in older women. Am J Respir Crit Care Med 2009;179(11):999-1003.

4. Huovinen E, Kaprio J, Koskenvuo M. Factors associated to lifestyle and risk of adult onset asthma. Respir Med 2003;97(3):273-80.

5. Thomsen SF, Ulrik CS, Kyvik KO, Larsen K, Skadhauge LR, Steffensen IE, et al. Risk factors for asthma in young adults: a co-twin control study. Allergy 2006;61(2):229-33.

6. Clavel-Chapelon F, van Liere MJ, Giubout C, Niravong MY, Goulard H, Le Corre C, et al. E3N, a French cohort study on cancer risk factors. E3N Group. Etude Epidémiologique auprès de femmes de l'Education Nationale. Eur J Cancer Prev 1997; 6(5):473-8.

7. Pols MA, Peeters PH, Ocké MC, Slimani N, Bueno-de-Mesquita HB, Collette HJ. Estimation of reproducibility and relative validity of the questions included in the EPIC Physical activity questionnaire. Int J Epidemiol 1997;26(Suppl. 1):S181-9.

8. Ainsworth BE, Haskell WL, Whitt MC, Irwin ML, Swartz AM, Strath SJ, et al. Compendium of physical activities: an update of activity codes and MET intensities. Med Sci Sports Exerc 2000;32(9 Suppl.):S498-504.

9. Ferris BG. Epidemiology standardization project (American Thoracic Society). Am Rev Respir Dis 1978;118(6 Pt 2):1-120.

10. Camargo CA, Weiss ST, Zhang S, Willett WC, Speizer FE. Prospective study of body mass index, weight change, and risk of adult-onset asthma in women. Arch Intern Med 1999; 159(21):2582-8.

11. Pekkanen J, Sunyer J, Anto JM, Burney P. European Community Respiratory Health Study. Operational definitions of asthma in studies on its aetiology. Eur Respir J 2005;26(1):28-35.

12. Andersen LB. Relative risk of mortality in the physically inactive is underestimated because of real changes in exposure level during follow-up. Am J Epidemiol 2004;160(2):189-95.

13. Haskell WL, Lee IM, Pate RR, Powell KE, Blair SN, Franklin BA, et al. Physical activity and public health: updated recommendation for adults from the American College of Sports Medicine and the American Heart Association. Med Sci Sports Exerc 2007;39(8):1423-34. 